ITEJ Desember-2019, Volume 4 Nomor 2 Page 114 - 122

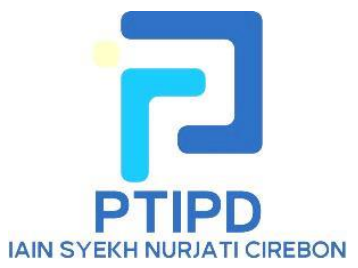

ITEJ

Information Technology Engineering Journals

elSSN : $\underline{2548-2157}$

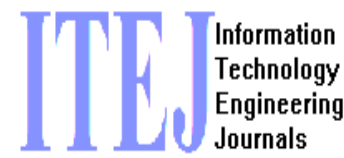

Url : https://syekhnurjati.ac.id/journal/index.php/itej

Email : itej@syekhnurjati.ac.id

\title{
Moving Object Detection on CCTV Surveillance Using the Frame Difference Method
}

\author{
Saluky Saluky \\ Tadris Matematika \\ IAIN Syekh Nurjati Cirebon \\ luke4line@gmail.com
}

\begin{abstract}
In today's computer vision research, many build systems for observing humans and understanding their appearance, activities, and behavior that provide sophisticated interfaces for interacting with humans, and create plausible human models for various purposes. This paper presents a simple algorithm for detecting moving objects from a static background based on frame differences. First, the first frame is captured via a static camera such as Closed Circuit Television (CCTV) after which a sequence of frames is taken periodically. Second, the absolute difference is calculated between successive frames and the difference in images is stored in the system. Third, the difference image is converted into a gray image and then translated into a binary image. Finally, morphological filtering is carried out to remove noise. In the last process, moving objects can be detected in conditions that do not change much apart from moving objects.
\end{abstract}

Keyword: Computer Vision, Frame Difference, Motion Detection

\section{INTRODUCTION}

Perkembangan penelitan visi computer berkembang sangat pesat dalam beberapa tahun terakhir[1]. Deteksi dan pemahaman suatu objek menjadi topic yang paling banyak dikembangkan ditambah lagi penggunan CCTV yang semakin masif yang dilakukan oleh pemerintah, swasta dan masyarakat untuk mengawasi lingkungan sekitarnya[2] menjadikan sumber data yang melimpah yang dapat diteliti lebih lanjut[3].

Tujuan dari deteksi gerakan adalah untuk mengenali gerakan objek yang ditemukan pada dua gambar yang diberikan yaitu background dan foreground. Selain itu, menemukan gerakan objek dapat berkontribusi pada pengenalan objek. Oleh karena itu, tujuan utama dari penelitian ini adalah untuk mengenali piksel yang dimiliki oleh objek yang sama. Namun, penelitian ini didasarkan pada asumsi berikut: 
- Kamera statis seperti CCTV dan terpasang dengan baik karena kestabilan adalah kunci jika ingin mengisolasi gerakan.

- Cahaya stabil, tidak berkedip

- Latar belakang kontras

- Kecepatan dan resolusi bingkai kamera tinggi

Saat ini metode yang digunakan dalam deteksi objek bergerak terutama metode background subraction[4], metode pengurangan latar belakang dan metode aliran optik. Metode aliran optik adalah menghitung bidang aliran optik citra, dan melakukan pemrosesan cluster sesuai dengan karakteristik distribusi aliran optik citra.

Metode ini dapat memperoleh informasi pergerakan yang lengkap dan mendeteksi objek bergerak dari latar belakang dengan lebih baik. Metode pengurangan latar belakang menggunakan metode perbedaan gambar saat ini dan gambar latar belakang untuk mendeteksi objek bergerak, dengan algoritma sederhana, tetapi sangat sensitif terhadap perubahan lingkungan luar dan memiliki kemampuan anti-interferensi yang buruk. Dalam metode pengurangan bingkai, keberadaan objek bergerak ditentukan dengan menghitung selisih dua gambar yang berurutan. Sistem deteksi gerakan apa pun yang didasarkan pada pengurangan latar belakang perlu menangani sejumlah situasi kritis seperti:

- Noise gambar, karena kualitas sumber gambar yang buruk;

- Variasi bertahap dari kondisi pencahayaan di tempat kejadian

- Gerakan kecil benda non-statik seperti cabang pohon dan semak yang tertiup angin;

- Daerah bayangan diproyeksikan oleh objek latar depan dan dideteksi sebagai objek bergerak.

Tujuan utama dari penelitian ini adalah untuk mengembangkan algoritma yang dapat mendeteksi objek bergerak pada jarak tertentu untuk aplikasi pelacakan objek. Sisa makalah telah disusun sebagai berikut: bagian 2 meliputi survei literatur, bagian 3 meliputi deteksi benda bergerak, bagian 4 menyajikan hasil percobaan, bagian 5 menyimpulkan makalah dan referensi diberikan di bagian akhir.

\section{RELATED WORK}

Pentingnya dan popularitas analisis gerak telah menghasilkan beberapa penelitian sebelumnya seperti yang telah ditunjukan oleh wang dan Zao[5] menggunakan background subtraction untuk Analisis gambar, misalnya, melanjutkan analisis gerak area sensitif yang ditentukan dalam rentang gambar dan menyediakan fungsi video, pelacakan target, dan hubungan alarm tertentu. Dalam urutan video ini terdiri dari rangkaian gambar video yang berisi fitur informasi geometri target, mengekstrak informasi yang relevan untuk menganalisis gerakan target kemudian mendapatkan hasil deteksi. Rasio kompresi meningkat pesat. 


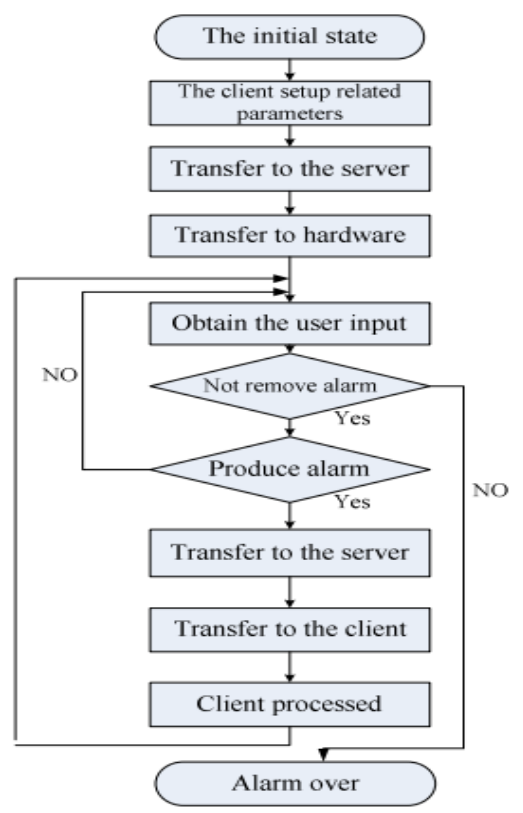

Gambar 1 : Flowchart deteksi gerakan[5]

Pada penelitian lain Rikebe dan Patil[6] menyajikan deteksi gerakan dengan mengembangkan algoritma baru berdasarkan algoritma pengurangan latar belakang. Dalam model latar belakang pertama yang dapat diandalkan berdasarkan statistik digunakan. Setelah itu pengurangan antara gambar saat ini dan gambar latar belakang dilakukan berdasarkan ambang batas. Kemudian dilakukan deteksi objek bergerak. Setelah itu, pemfilteran morfologi dimulai untuk menghilangkan kebisingan dan mengatasi kesulitan gangguan latar belakang.

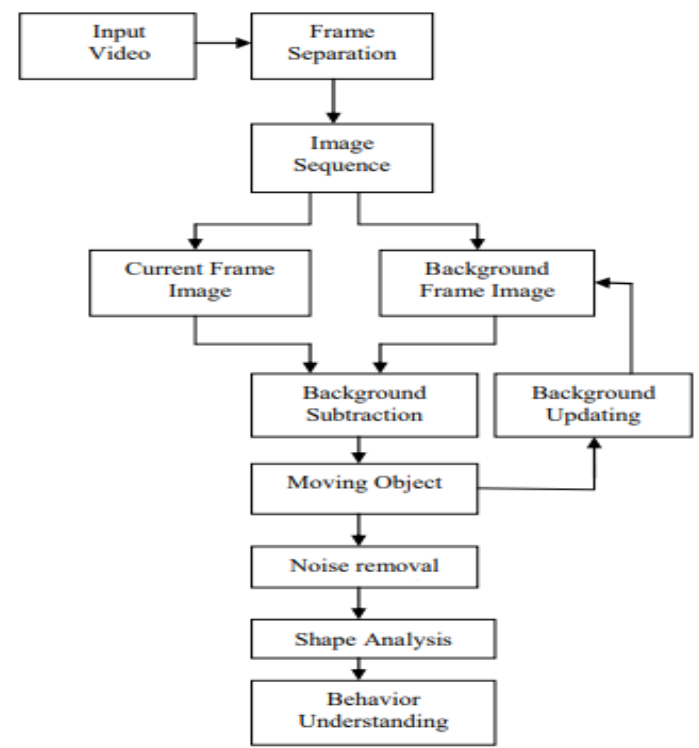

Gambar 2 : Flowchart mengartikan perilaku[6] 
K.Kavitha et al[7] menyajikan deteksi gerakan dengan mengatasi kelemahan algoritma pengurangan latar belakang. Dalam hal ini, algoritma pengurangan latar belakang yang dihitung secara efisien telah digunakan, yang mampu mengatasi masalah perubahan iluminasi lokal seperti bayangan dan sorotan serta perubahan iluminasi global.

Shafie et al[8] menyajikan deteksi gerakan menggunakan metode aliran optik. Aliran optik dapat timbul dari gerak relatif benda dan penampil sehingga dapat memberikan informasi penting tentang penataan spasial benda yang dilihat dan laju perubahan susunan tersebut. Diskontinuitas dalam aliran optik dapat membantu membagi gambar ke wilayah yang sesuai dengan objek yang berbeda.

Shuigen et al[9] mengembangkan deteksi gerak dengan menggunakan metode yang didasarkan pada perbedaan temporal dan medan aliran optik. Ia pandai beradaptasi dengan lingkungan dinamis. Pertama, citra diferensial absolut dihitung dari dua citra abu-abu yang berurutan. Gambar diferensial absolut difilter dengan filter low pass dan diterjemahkan ke dalam gambar biner. Kedua, bidang aliran optik dihitung dari urutan gambar dengan algoritma Hron. Ketiga, luas benda bergerak ditemukan oleh tepi terindeks dan bidang aliran optik.

Devi et al[10] menyajikan deteksi gerakan menggunakan pencocokan bingkai latar belakang. Metode ini adalah metode yang sangat efisien untuk membandingkan nilai piksel gambar dalam bingkai diam berikutnya yang diambil setelah setiap dua detik dari kamera. Dua bingkai diperlukan untuk mendeteksi gerakan. Bingkai pertama disebut bingkai referensi dan bingkai kedua disebut bingkai masukan berisi benda bergerak. Kedua frame tersebut dibandingkan dan perbedaan nilai piksel ditentukan.

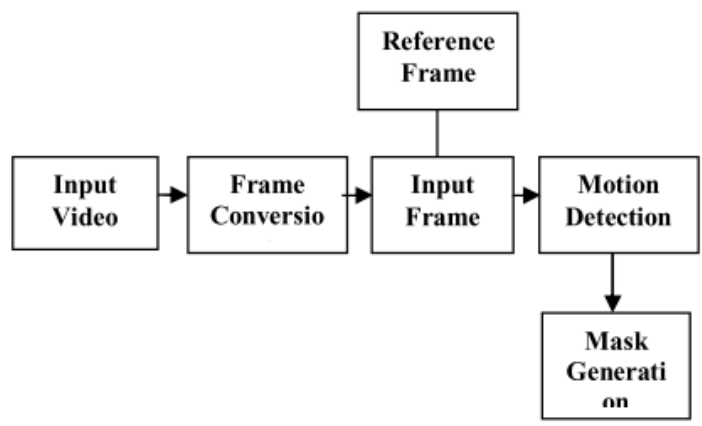

Gambar 3 : Flowchart deteksi gerakan dengan pencocokan frame background

Lu et al[11] menyajikan deteksi gerakan dengan mengusulkan algoritma deteksi waktu nyata. Dalam algoritma ini mengintegrasikan metode perbedaan waktu, metode aliran optik dan metode penyaringan latar belakang ganda (DBF) dan metode pemrosesan morfologi untuk mencapai kinerja yang lebih baik. 


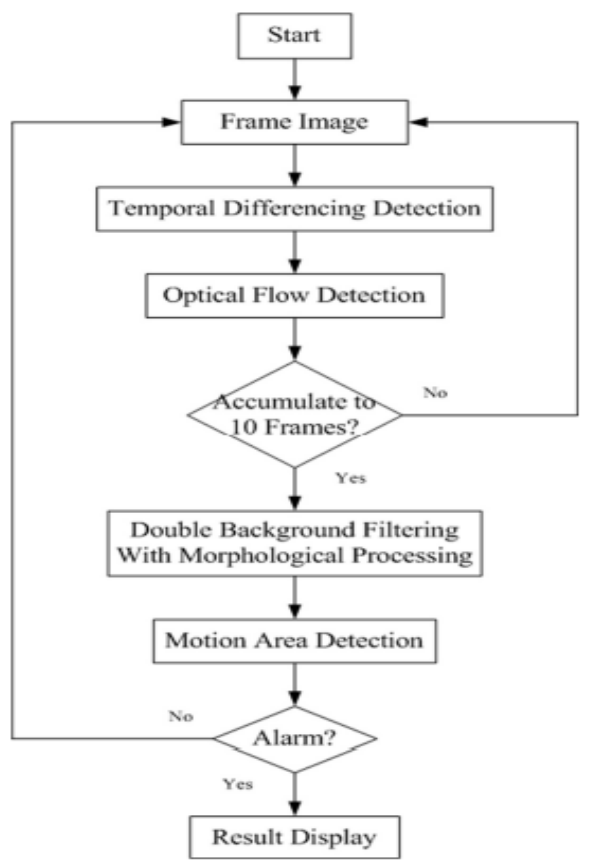

Gambar 4 : Flowchart integrasi frame difference, optical flow dan double filtering background

\section{METHOD}

Deteksi objek bergerak dari rangkaian frame yang ditangkap dari kamera statis banyak dilakukan dengan metode frame difference[12]. Pendekatan ini bertujuan untuk mendeteksi objek bergerak dari selisih antara frame eksisting dan frame referensi[13]. Metode perbedaan bingkai adalah metode umum untuk mendeteksi gerakan. Metode ini mengadopsi perbedaan berbasis piksel untuk mencari objek bergerak.

\section{Selisih Dua Bingkai Berturutan}

$\mathrm{I}_{\mathrm{k}}$ seharusnya menjadi nilai bingkai ke-k dalam urutan gambar. $\mathrm{I}_{\mathrm{k}+1}$ adalah nilai bingkai $(\mathrm{k}+1)$ dalam urutan gambar. Gambar diferensial absolut didefinisikan sebagai berikut:

$I_{d(k, k+1)}=\left|I_{k+1}-I_{k}\right|$

\section{Transformasi citra diferensial mutlak menjadi citra abu-abu}

Terdapat lubang pada area objek bergerak, dan kontur objek bergerak tidak tertutup. Gambar diferensial mutlak diubah menjadi gambar abu-abu untuk memfasilitasi operasi selanjutnya.

RGB to Gray

$\mathrm{Y} \leftarrow 0.299 * R+0.587 * G+0.114 * B$

\section{Filtering dan Binarizing Transformed Grey Image}

Untuk menghilangkan lubang, gambar dilewatkan melalui filter low pass Gauss.

$\mathrm{I}_{\mathrm{d} 1}$ didapat dengan memfilter gambar abu-abu. Sekarang $\mathrm{I}_{\mathrm{d} 1}$ image binari menggunakan ambang biner dan mendapatkan citra biner $\mathrm{I}_{\mathrm{d} 2}$. 
Berikut ini flowchart dari metode yang diusulkan

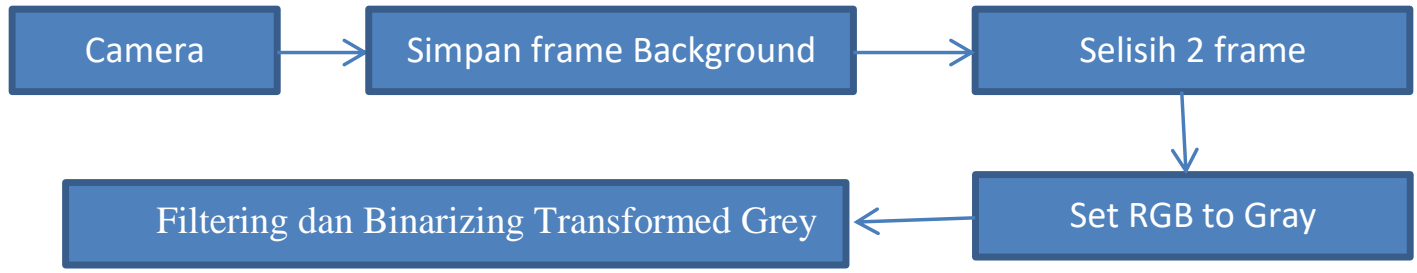

Gambar 5 : Flowchart frame diference

\section{RESULT}

Pada percobaan dengan mengamati dua frame tanpa ada objek yang bergerak, hasil urutan citra yang dihitung dengan metode berikut adalah pada gambar berikut.

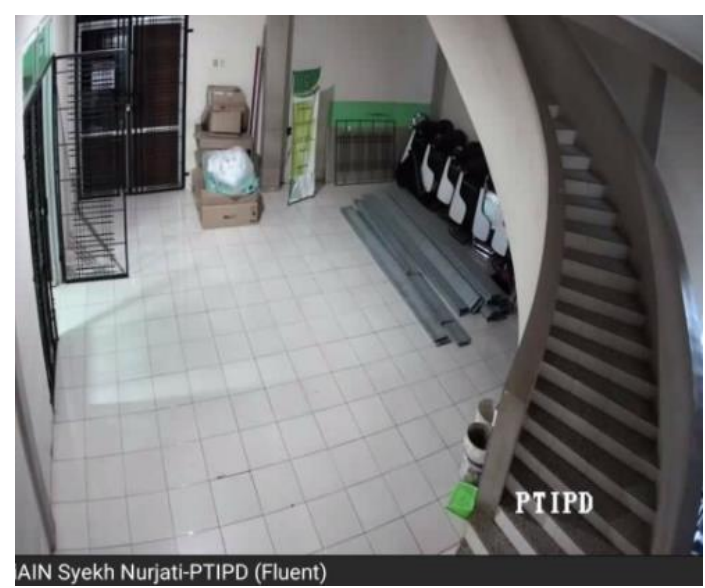

Input frame(a)

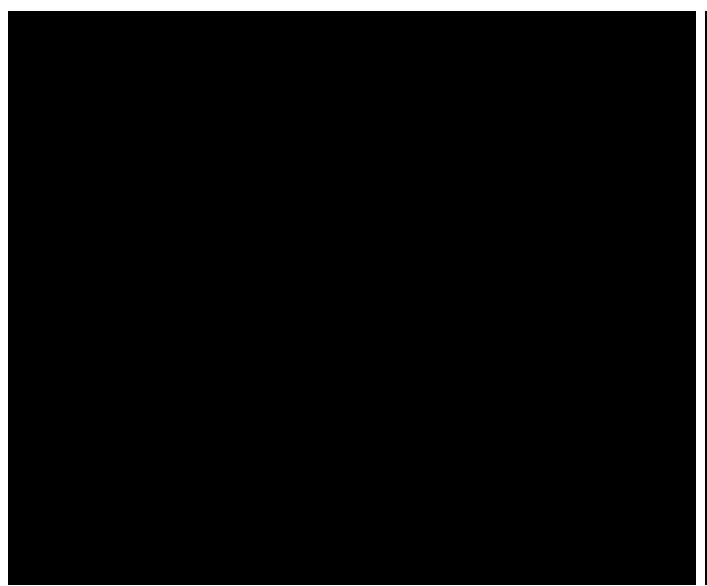

Perbedaan antara dua tampilan bingkaibenda bergerak

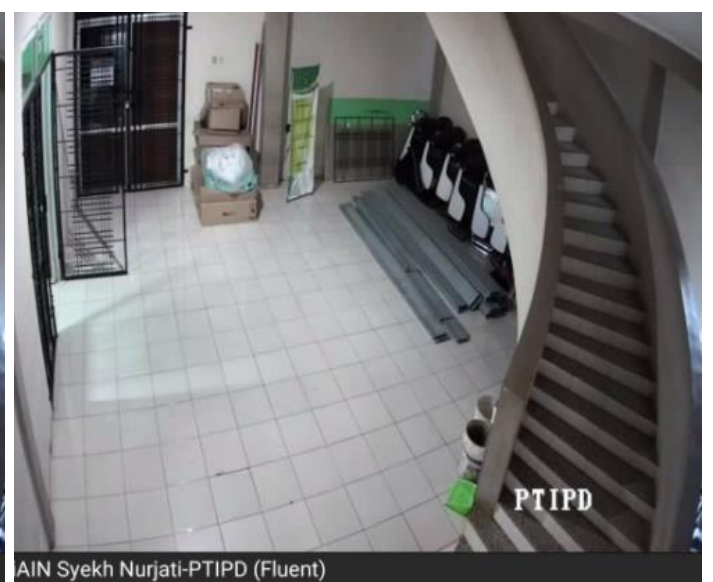

Input frame(b)

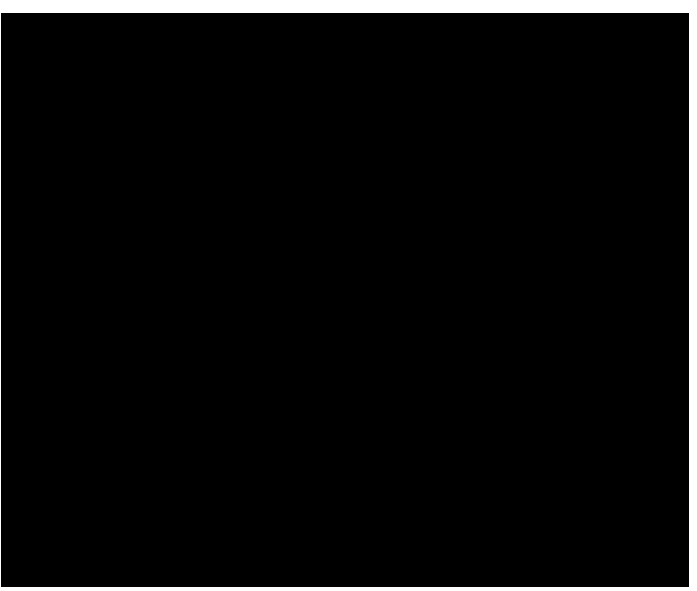

Citra biner dari citra perbedaan.

Gambar 6 : Hasil percobaan perbedaan antara 2 frame tanpa objek bergerak 
Ketika ada gerakan dalam adegan maka gambar biner selisih kedua bingkai tersebut menunjukkan gerakan yang berwarna putih dan tidak ada perubahan menunjukkan warna hitam, terlihat seperti gambar dibawah ini.

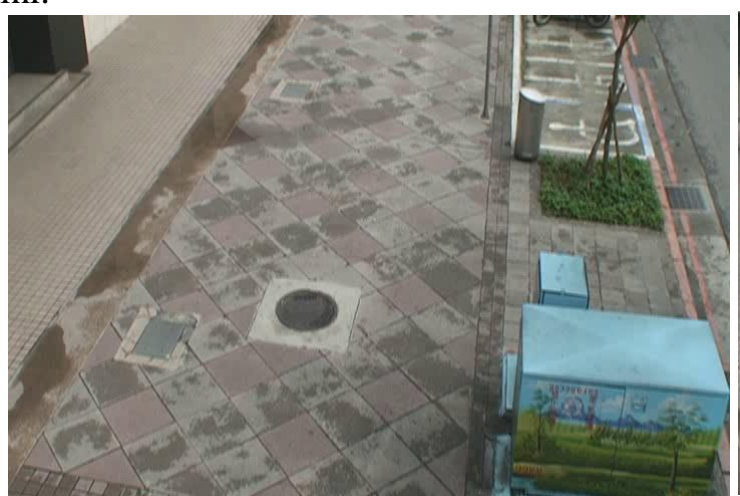

Input frame(a)

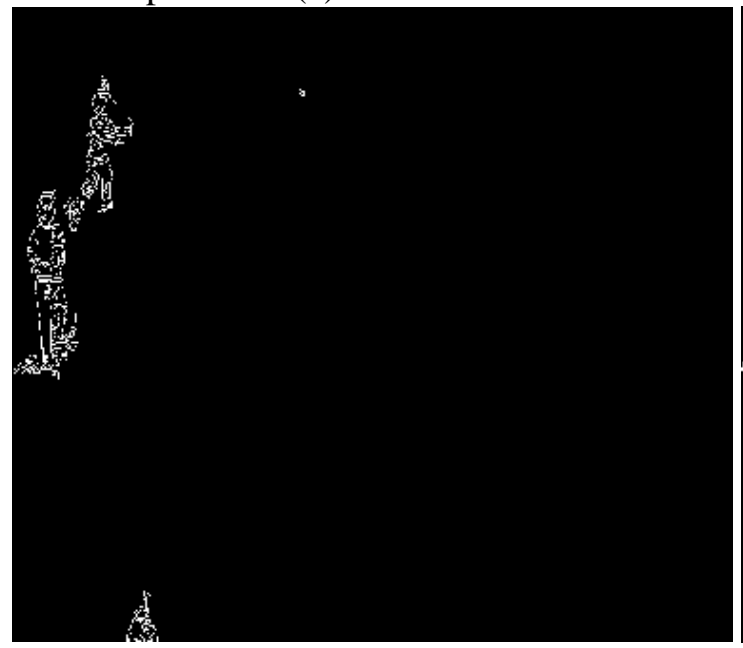

Perbedaan antara dua tampilan bingkaibenda bergerak

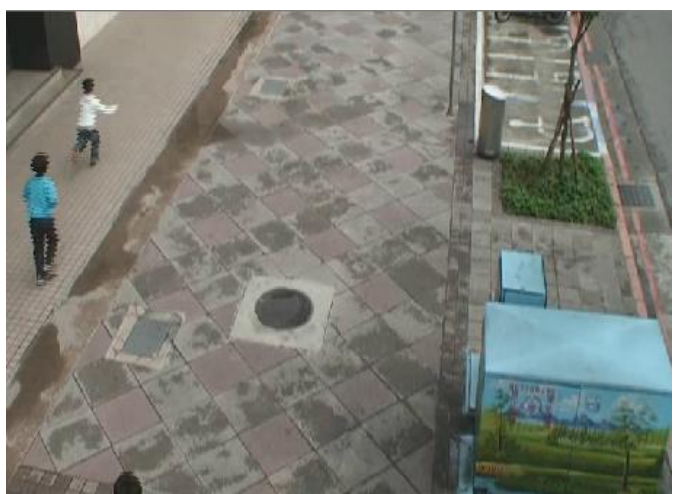

Input frame(b)

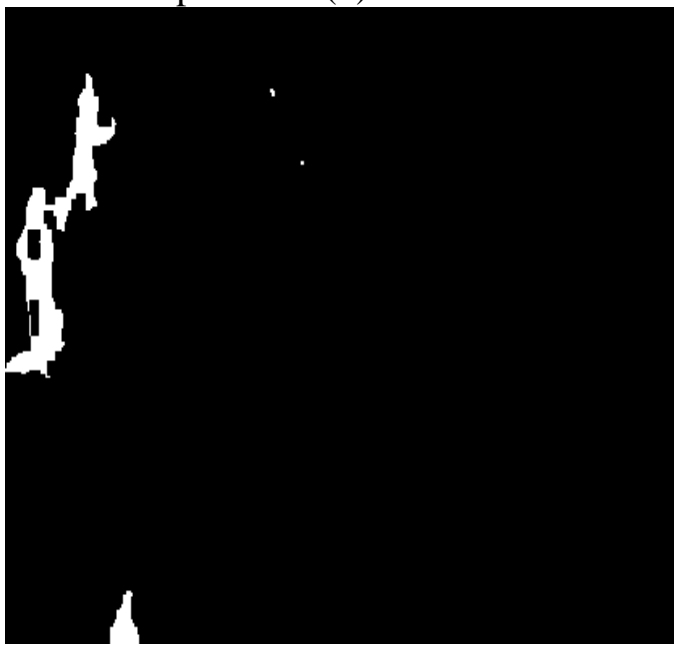

Citra biner dari citra perbedaan.

Gambar 7 : Hasil percobaan 2 frame saat ada objek bergerak

Metode yang diusulkan juga mendeteksi gerakan akibat gerakan di udara. Saat udara bergerak, kamera tidak berada pada posisi statis sehingga pada saat tidak ada pergerakan benda maka juga akan menghasilkan gerakan dan menunjukkan kelemahan pada gambar keluaran biner.

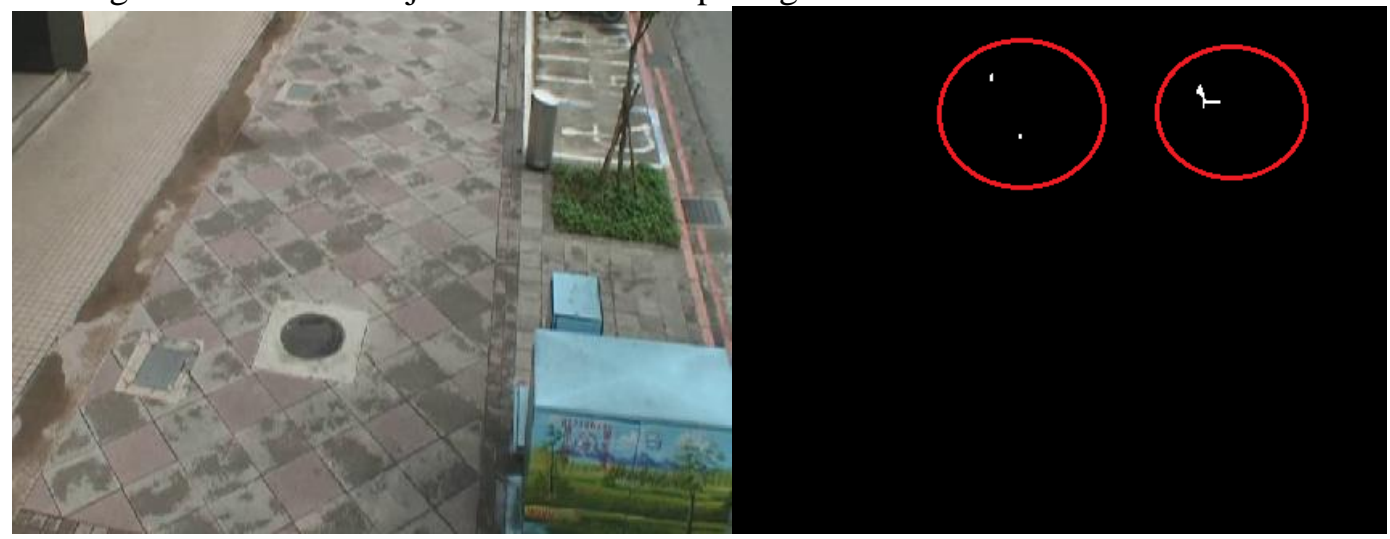

Gambar 8 : Kelemahan frame difference karena gangguan udara 
Keterbatasan algoritma ini terutama tercermin dalam fakta bahwa biasanya tidak mungkin mendapatkan informasi edge yang lengkap saat target bergerak saat mengekstraksi objek bergerak. Jika warna latar belakang mirip dengan warna target, informasi dalam target bergerak yang terdeteksi sering dianggap sebagai informasi latar belakang, sehingga sulit untuk mengekstrak target secara akurat.

\section{CONLUSION}

Dalam penelitian ini, objek bergerak dideteksi dengan metode deteksi gerak, yang terdiri dari metode perbedaan bingkai dan operasi morfologi.ini adalah pekerjaan awal mempelajari prinsip metode perbedaan bingkai dan menyelesaikan berbagai masalah. Percobaan menunjukkan bahwa metode tersebut memiliki kinerja dan efisiensi yang baik namun begitu masih memiliki keterbatasan terhadap pencahayaan dan gangguan cuaca. Peningkatan masa depan mungkin termasuk mengingatkan pengguna dengan mengirim warning secara realtime saat ada perilaku mencurigakan tertangkap kamera.

\section{REFERENSI}

[1] Z. Zhang et al., "Deep learning based human action recognition: A survey," in 2017 Chinese Automation Congress (CAC), 2017, no. 2014ggx10 3038, hal. 3780-3785, doi: 10.1109/CAC.2017.8243438.

[2] Saluky Saluky; Suhono Harso Supangkat; Fetty Fitriyanti Lubis, "Moving Image Interpretation Models to Support City Analysis," 2018 Int. Conf. ICT Smart Soc., 2018.

[3] H. Wei, "A block-wise frame difference method for real-time video motion detection," no. August, hal. 1-13, 2018, doi: 10.1177/1729881418783633.

[4] C. S. Rao dan P. Darwin, "Frame Difference And Kalman Filter Techniques For Detection Of Moving Vehicles In Video Surveillance,” vol. 2, no. 6, hal. 1168-1170, 2012.

[5] Z. Wang, Y. Zhao, J. Zhang, dan Y. Guo, "Research on motion detection of video surveillance system," Proc. - 2010 3rd Int. Congr. Image Signal Process. CISP 2010, vol. 1, hal. 193-197, 2010, doi: 10.1109/CISP.2010.5647987.

[6] R. S. Rakibe dan B. D. Patil, "Background Subtraction Algorithm Based Human Motion Detection," Int. J. Sci. Res. Publ., vol. 3, no. 5, hal. 3-6, 2013.

[7] K.Kavitha;A.Tejaswini, "VIBE: Background Detection and Subtraction for Image Sequences in Video," Int. J. Comput. Sci. Inf. Technol., vol. 3, no. 5, hal. 5223-5226, 2012, doi: 10.1111/den.13249.

[8] A. A. Shafie, F. Hafiz, dan M. H. Ali, "Motion detection techniques using optical flow," World Acad. Sci. Eng. Technol., vol. 56, no. 8, hal. 559-561, 2009, doi: 10.5281/zenodo.1071465.

[9] S. Wei, Z. Chen, dan H. Dong, "Motion detection based on temporal difference method and optical flow field," 2nd Int. Symp. Electron. Commer. Secur. ISECS 2009, vol. 2, no. May, hal. 85-88, 2009, doi: 10.1109/ISECS.2009.62.

[10] K. S. Devi, N. Malmurugan, dan M. Manikandan, "Object motion detection in video frames using background frame matching," Int. J. Comput. Trends Technol., vol. 4, no. 6, hal. 1928-1931, 2013.

[11] N. Lu, J. Wang, Q. H. Wu, dan L. Yang, “An Improved Motion Detection Method for Real-Time Surveillance," IAENG Int. J. Comput. Sci., vol. 35, no. 1, hal. 1-10, 2008. 
[12] L. Shang, F. You, C. Han, X. Wang, dan S. Zhao, "Optimization of Three - Frame Difference Method and Improvement of Pedestrian Detection Code Book Optimization of Three - Frame Difference Method and Improvement of Pedestrian Detection Code Book," 2019, doi: 10.1088/1742-6596/1302/2/022014.

[13] N. Singla, "Motion Detection Based on Frame Difference Method," vol. 4, no. 15, hal. 1559-1565, 2014. 